\title{
Implications of constructed biologic subtype and its relationship to locoregional recurrence following mastectomy
}

Laura S Dominici', Elizabeth A Mittendorf ${ }^{1}$, Xumei Wang ${ }^{3}$, Jun Liư ${ }^{3}$, Henry M Kuerer ${ }^{1}$, Kelly K Hunt ${ }^{1}$, Abenaa Brewster ${ }^{2}$, Gildy V Babiera ${ }^{1}$, Thomas A Buchholz ${ }^{4}$, Funda Meric-Bernstam ${ }^{1}$ and Isabelle Bedrosian ${ }^{\text {** }}$

\begin{abstract}
Introduction: We examined the prognostic value of biologic subtype on locoregional recurrence (LRR) after mastectomy in a cohort of low risk women who did not receive adjuvant radiation therapy.

Methods: A total of 819 patients with invasive breast cancer underwent mastectomy from January 2000 through December 2005. No patient received preoperative chemotherapy. Estrogen receptor (ER) receptor, progesterone receptor (PR) and human epidermal growth factor receptor 2 (HER2) status were used to construct the following 4 subtypes: i) ER+ or PR+ and HER2- (HR+/HER2-), ii) ER+ or PR+ and HER2+ (HR+/HER2+), iii) ER- and PR- and HER2+ (HR-/HER2+)and iv) ER- and PR- and HER2- (HR-/HER2-). LRR-free survival was estimated by the Kaplan-Meier method. Cox proportional hazard models were used to evaluate the association between time-to-event outcomes and patient prognostic factors.
\end{abstract}

Results: At a median follow-up of 58 months, five-year cumulative incidence of LRR for the entire cohort was $2.5 \%$. Subtype specific LRR rates were 1\% for HR+/HER2-, 6.5\% in HR+/HER2+, 2\% for HR-/HER2+ and 10.9\% for HR-/ HER2- $(P<0.01)$. In HER-2+ patients (irrespective of ER/PR status), trastuzumab therapy was not associated with LRR-free survival. On multivariate analysis, one to three positive lymph nodes (HR 4.75 (confidence interval (Cl) 1.75 to $12.88, P<0.01)$, $\geq 4$ positive lymph nodes (HR23.4 (Cl 4.64 to 117.94, $P<0.01)$, HR+/HER2+ (HR 4.26 (Cl 1.05 to 17.33), $P=0.04$ ), and HR-/HER2- phenotype (HR 13.87 (Cl 4.96 to 38.80), $P<0.01$ ) were associated with shorter LRRfree survival whereas age $>50$ at diagnosis (HR $0.31(\mathrm{Cl} 0.12$ to 0.80$), P=0.02$ ) was associated with improved LRRfree survival. Among the HR-/HER2- subtypes, five-year LRR incidence was $23.4 \%$ in patients with positive lymph nodes compared to $7.8 \%$ for lymph node negative patients $(P=0.01)$, although this association did not reach significance when the analysis was limited to HR-/HER2- women with only one to three positive lymph nodes (15.6\% versus $7.8 \%, P=0.11)$

Conclusions: Constructed subtype is a prognostic factor for LRR after mastectomy among low risk women not receiving adjuvant radiation therapy, although rates of LRR remain low across subtypes. Patients with node positive, HR-/HER2- type tumors were more likely to experience LRR following mastectomy alone. Prospective studies to further investigate the potential benefit of adjuvant radiation therapy in these women are warranted.

\footnotetext{
* Correspondence: ibedrosian@mdanderson.org

'Department of Surgical Oncology, University of Texas MD Anderson Cancer

Center, 1515 Holcombe Blvd, Houston, TX 77030, USA

Full list of author information is available at the end of the article
} 


\section{Introduction}

The identification of biologic subtypes of breast cancer has provided an important window into the underlying heterogeneity of this cancer and has provided a new paradigm for classification of this disease [1]. Since the initial demonstration that these molecular subtypes correlated with differences in survival [2], other groups have similarly confirmed the clinical relevance of the biologic subtypes [3,4]. HER-2 amplified and basal subtypes are associated with significantly worse overall survival while the luminal A subtype has a higher expression of genes related to the estrogen receptor and is associated with the best prognosis. Although the initial description of molecular profiles of breast cancer was based on transcriptional profiling, the practical challenges of this approach have led many to use clinical approximations of these subtypes primarily using ER, PR and HER2. Importantly, much of the clinical data on patient related outcomes based on subtype utilizes this clinical approximation, underscoring that they yield results similar to those of studies utilizing the full gene profile [5-7].

The impact of biologic subtypes on local regional recurrence (LRR) outcomes has been less well studied. Recent data in women with early stage breast cancer undergoing breast conserving therapy suggests that these biologic subtypes also confer a similar risk profile for local recurrence as they do for distant disease [7-9]. Among women undergoing mastectomy, similar trends appear to hold $[9,10]$.

The role of chest wall and regional nodal irradiation following mastectomy continues to evolve [11]. In many cases, women undergoing mastectomy will not require radiation therapy. However, based on clinical features, some women felt to be at high risk for recurrence following mastectomy will be recommended for post-mastectomy radiation therapy (PMRT). Biologic subtype of breast cancer is not currently considered in the indications for PMRT, as increased risk for LRR based on subtype has not been as well established. The objectives of this study were to determine the relevance of constructed biologic subtype (using ER, PR and HER2 as surrogates) in predicting LRR following mastectomy in a cohort of women deemed clinically low risk for locoregional recurrence who, thus, did not undergo PMRT.

\section{Materials and methods Patient selection}

The study cohort included 819 women with invasive breast cancer who underwent mastectomy at the University of Texas MD Anderson Cancer Center from January 2000 through December 2005. Seven patients who presented with breast cancer were found to have a contralateral cancer on imaging at presentation or on prophylactic mastectomy pathology. In these patients, the index breast cancer was used for analysis. Patients with recurrent ipsilateral breast cancer after previous breast conservation therapy were excluded. Two patients with Stage IV disease were included in this analysis. Neither received PMRT and both were found to be Stage IV on postoperative staging work-up. Patients receiving preoperative systemic therapy were excluded from this analysis. No patient in this study received adjuvant radiation therapy.

This study was approved by the MD Anderson Cancer Center Institutional Review Board and waiver of consent provided by the IRB; specific consent from the patients to participate in the study and consent to publish the resulting data was not required by the IRB.

\section{Margin assessment}

Margins were deemed positive only if there was tumor on ink. Close margins were defined as tumor within 2 $\mathrm{mm}$ of ink. DCIS or invasive cancer $>2 \mathrm{~mm}$ from ink was classified as a negative margin.

\section{Treatment}

Adjuvant systemic therapy was administered at the discretion of the treating oncologist. Although adjuvant trastuzumab was not routinely used during the time of this study, 28 out of 108 HER2 + patients in our cohort were additionally treated with adjuvant trastuzumab. Women with hormone receptor positive tumors (ER and or PR $>10 \%$ ) were advised to receive adjuvant hormonal therapy. Twelve patients with ER negative (< $10 \%)$ and PR negative $(<10 \%)$ cancers received hormonal therapy, most for weakly hormone receptor positive tumors ( $1 \%$ to $9 \%$ positive).

\section{Follow up}

Patients were generally seen in follow-up every three months for the first two years and, subsequently, every six months. Patients who did not routinely follow-up at MD Anderson Cancer Center were contacted by phone or mail for follow-up information. Follow-up time was counted from date of diagnosis to the date of death, date of first event or last confirmed date of breast cancer disease-free status. The median follow up time was 58 months (range 2.4 to 122 months).

\section{Classification of biologic subtype}

Four subtypes were constructed based on the receptor status of the primary tumor: i) ER+ or PR+ and HER2(HR+/HER2-), ii) ER+ or PR+ and HER2+ (HR+/HER2 + ), iii) ER- and PR- and HER2+ (HR-/HER2+)and iv) ER- and PR- and HER2- (HR-/HER2-). ER and PR were 
considered positive if immunohistochemistry (IHC) staining was $10 \%$ or greater [12]. An IHC score of $3+$ or HER2 amplification by fluorescence in situ hybridization (FISH) score was used to determine HER2 positive status. In the setting of 2+ IHC staining and no FISH data, tumors were considered negative for HER2 [13]. Patients with unknown biologic subtype constituted those where HER2 testing was not performed. These patients were included when characterizing the patient population as a whole, but were excluded from subtype specific analyses.

\section{Statistical analysis}

The primary end point of this study was time to local or regional recurrence, defined as biopsy-proven recurrence in the chest wall, skin, axilla, infraclavicular nodes, internal mammary nodes or supraclavicular nodes. The local or regional recurrence free time was defined as the time interval from the surgery date to the local or regional recurrence date, death date or last follow-up date, whichever occurred first.

Pearson's Chi-Square tests were used to assess the association of clinical variables among subtypes. The Kaplan-Meier method [14] was used to estimate the probability of overall survival as well as local or regional recurrence-free survival. The long-rank test [15] was used to compare the time-to-event outcomes among subgroups of patients. The Cox proportional hazards models [16] were used to assess the association between the time-to-event outcomes and patient prognostic factors as well as constructed subtypes. Backward model selection methods were used to determine the final fitted models. $P$-values less than 0.05 were deemed statistically significant. All statistical analyses were conducted in SAS 9.1 for Windows (SAS Institute Inc., Cary, NC).

\section{Results}

The characteristics of the 819 women in this analysis are described in Table 1. The majority of patients presented with early stage, node negative breast cancer. In this mostly post-menopausal cohort, $80 \%$ had hormone sensitive tumors as measured by ER or PR staining. Thirteen percent of the women had HER2 overexpressing tumors; of these, only one quarter received trastuzumab therapy.

There were significant differences across the constructed subtypes with regard to clinical, pathological and treatment variables (Table 2), including median age at presentation $(P<0.01)$, number of positive nodes $(P$ $=0.02)$ and grade $(P<0.01)$. Women with HR-/HER $2+$ tumors tended to be younger, while those with HR-/ HER2- tumors has the lowest incidence of nodal involvement. Compared to all other cohorts, women with HR +/HER2- had the lowest probability of grade 3 tumors.
Table 1 Patient baseline characteristics (number $=819$ ).

\begin{tabular}{|c|c|c|}
\hline Characteristic & Number & $\%$ \\
\hline \multicolumn{3}{|l|}{ Age at diagnosis } \\
\hline$<50$ & 290 & 35.4 \\
\hline$>50$ & 529 & 64.6 \\
\hline \multicolumn{3}{|l|}{ T stage } \\
\hline $\mathrm{T} 1$ & 613 & 74.8 \\
\hline T2 & 195 & 23.8 \\
\hline $\mathrm{T} 3$ & 11 & 1.4 \\
\hline \multicolumn{3}{|l|}{ Number of positive nodes } \\
\hline 0 & 586 & 71.6 \\
\hline $1-3$ & 219 & 26.7 \\
\hline$>4$ & 10 & 1.2 \\
\hline No nodes sampled & 4 & 0.5 \\
\hline \multicolumn{3}{|l|}{ Grade } \\
\hline 1 & 84 & 10.3 \\
\hline 2 & 431 & 52.6 \\
\hline 3 & 300 & 36.6 \\
\hline Unknown & 4 & 0.5 \\
\hline ER or PR positive & 656 & 80.1 \\
\hline HER2 positive & 109 & 13.3 \\
\hline LVI present & 137 & 16.7 \\
\hline Hormonal therapy received & 553 & 67.5 \\
\hline Chemotherapy received & 389 & 47.5 \\
\hline $\begin{array}{l}\text { Trastuzumab therapy received (if HER2 positive, Number } \\
=108 \text { ) }\end{array}$ & 28 & 25.9 \\
\hline \multicolumn{3}{|l|}{ Margins } \\
\hline Close or positive & 27 & 3.3 \\
\hline Negative & 791 & 96.6 \\
\hline Unknown & 1 & 0.1 \\
\hline \multicolumn{3}{|l|}{ Constructed subtype } \\
\hline HR+/HER2+ & 574 & 70 \\
\hline HR+HER2+ & 57 & 7 \\
\hline HR-/HER2+ & 51 & 6.2 \\
\hline HR-/HER2- & 94 & 11.5 \\
\hline Unknown & 43 & 5.3 \\
\hline
\end{tabular}

ER, estrogen receptor; HER2, human epidermal growth receptor 2; LVI, lymphovascular space invasion; PR, progesterone receptor.

As expected, the number of patients receiving hormonal therapy and chemotherapy was also significantly different (all $P<0.01$ ) with the majority of women with ER and/or PR positive tumors receiving endocrine therapy and the majority of patients with HER2+ (irrespective of ER/PR status) and HR-/HER2- tumors receiving chemotherapy.

With a median follow-up of 58 months, the five-year cumulative incidence of LRR was $2.5 \%$. For patients with HR+/HER2-, the five-year incidence of LRR was $1 \%(95 \% \mathrm{CI}, 0.1 \%$ to $1.9 \%)$, compared with $6.5 \%$ (95\%CI, 0 to $13.5 \%)$ in the HR+/HER2+ group, $2 \%(95 \% \mathrm{CI}, 0$ to $5.8 \%$ ) for HR-/HER $2+$ and $10.9 \%$ (95\% CI, 3.8 to $7.5 \%$ ) in the HR-/HER2- group $(P<0.01)$ (Table 2 and Figure $1)$. Although there were differences in overall survival 
Table 2 Patient characteristics by breast cancer subtype (Number $=819$ ).

\begin{tabular}{|c|c|c|c|c|c|c|}
\hline Variable & $\begin{array}{l}\text { All patients (Number } \\
=819)\end{array}$ & $\begin{array}{c}\text { HR+/HER2- } \\
\text { (Number = } \\
574)(\%)\end{array}$ & $\begin{array}{c}\text { HR+/HER2+ } \\
\text { (Number = } \\
57)(\%)\end{array}$ & $\begin{array}{c}\text { HR-/HER2+ } \\
\text { (Number = } \\
51)(\%)\end{array}$ & $\begin{array}{l}\text { HR-/HER2- } \\
\text { (Number = } \\
94)(\%)\end{array}$ & $\begin{array}{c}P- \\
\text { value }\end{array}$ \\
\hline Median age at diagnosis & 55 & 56 & 54 & 49 & 54 & $\begin{array}{c}< \\
0.01\end{array}$ \\
\hline $\mathrm{T} 1$ & 615 & $439(76.48)$ & $41(71.93)$ & $36(70.59)$ & $60(63.83)$ & 0.06 \\
\hline Positive lymph nodes & 230 & $164(28.57)$ & $25(43.86)$ & $14(27.45)$ & $19(20.21)$ & 0.02 \\
\hline$\geq 4$ positive lymph nodes & 10 & $7(1.22)$ & 0 & 0 & $3(3.19)$ & 0.25 \\
\hline Lymphovascular invasion & 137 & $89(15.51)$ & $16(28.07)$ & $13(25.49)$ & $16(17.02)$ & 0.07 \\
\hline Modified Black's nuclear grade 3 & 301 & $132(23.00)$ & $36(63.16)$ & $48(94.12)$ & $75(79.79)$ & $\begin{array}{c}< \\
0.01\end{array}$ \\
\hline Close or positive margins & 27 & $17(2.96)$ & 0 & $3(5.88 \%)$ & $5(5.32)$ & 0.21 \\
\hline Hormonal therapy & 556 & $473(82.40)$ & $50(87.72)$ & $5(9.80)$ & $6(6.38)$ & $\begin{array}{c}< \\
0.01\end{array}$ \\
\hline Chemotherapy & 390 & $235(40.94)$ & $42(73.68)$ & $38(74.51)$ & $64(68.09)$ & $\begin{array}{c}< \\
0.01\end{array}$ \\
\hline Median follow-up (months) & 58 & 58 & 55 & 62 & 53 & 0.11 \\
\hline $\begin{array}{l}\text { Locoregional recurrence incidence rate at } 60 \\
\text { months }(95 \% \mathrm{Cl})\end{array}$ & $\begin{array}{c}2.5 \% \\
(1.6 \% \text { to } 4.0 \%)\end{array}$ & $\begin{array}{c}1 \% \\
(0.1 \% \text { to } 1.9 \%)\end{array}$ & $\begin{array}{c}6.5 \% \\
(0 \text { to } 13.5 \%)\end{array}$ & $\begin{array}{c}2 \% \\
\text { (0 to } 5.8 \%)\end{array}$ & $\begin{array}{c}10.9 \% \\
(3.8 \% \text { to } 17.5 \%)\end{array}$ & $\begin{array}{c}< \\
0.01\end{array}$ \\
\hline $\begin{array}{l}\text { Local recurrence incidence rate at } 60 \text { months } \\
(95 \% \mathrm{Cl})\end{array}$ & $0.9 \%(0.5 \%$ to $2.1 \%)$ & $\begin{array}{c}0.5 \%(0.2 \% \text { to } \\
1.7 \%)\end{array}$ & $\begin{array}{c}4.7 \%(2.3 \% \text { to } \\
17.7 \%)\end{array}$ & $0 \%$ & $\begin{array}{c}2.6 \%(0.7 \% \text { to } \\
10.5 \%)\end{array}$ & 0.06 \\
\hline $\begin{array}{l}\text { Regional recurrence incidence rate at } 60 \\
\text { months }(95 \% \mathrm{Cl})\end{array}$ & $1.5 \%(0.9 \%$ to $2.8 \%)$ & $\begin{array}{c}0.5 \%(0.2 \% \text { to } \\
2.0 \%)\end{array}$ & $\begin{array}{c}1.8 \%(0.3 \% \text { to } \\
12.1 \%)\end{array}$ & $\begin{array}{l}2.0 \%(0.3 \% \\
\text { to13.4\%) }\end{array}$ & $\begin{array}{c}8.3 \%(4.2 \% \text { to } \\
16.1 \%)\end{array}$ & $\begin{array}{c}< \\
0.01\end{array}$ \\
\hline
\end{tabular}

$\mathrm{Cl}$, confidence interval; HER2, human epidermal growth receptor 2; HR, hormone receptor.

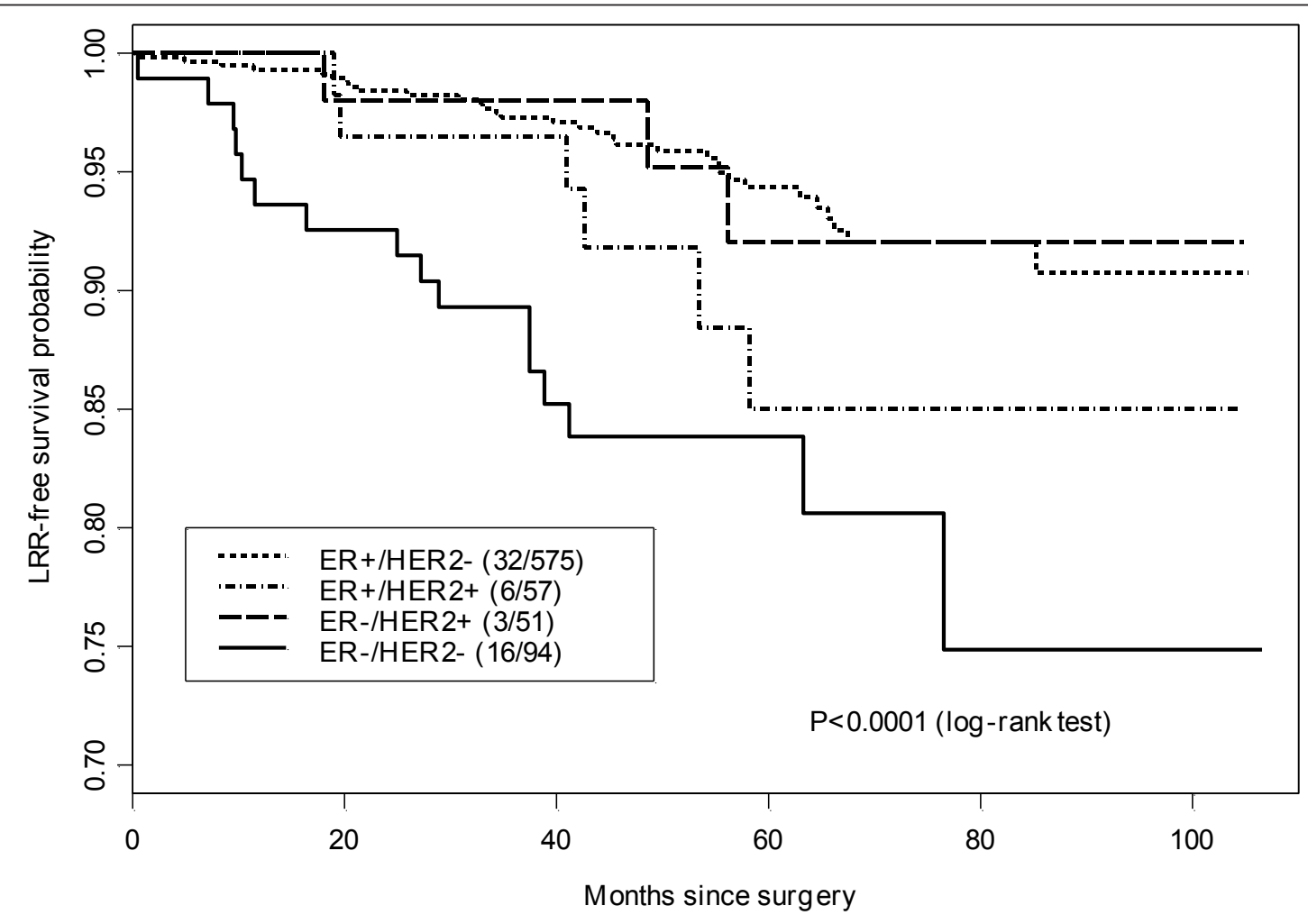

Figure 1 Log rank test of local regional recurrence free survival by tumor subtype. 
among the different subgroups, these did not reach statistical significance $(P=0.06)$ (Figure 2$)$.

On univariate analysis, younger age at presentation was associated with greater risk of LRR (HR 3.22 (95\% CI 1.28 to 8.33$), P=0.01$ ) whereas ER- or PR-positive tumors were associated with markedly lower risk of LRR (HR 0.15 (95\%CI 0.06 to 0.38), $P<0.01$ ) (Table 3). Significant predictors of locoregional failure also included increasing tumor size, nodal involvement, increasing pathologic stage, high grade and presence of lymphovascular space invasion (LVI) (all $P<0.05)$. Among the subtypes, HR-/HER2- had the highest risk of LRR (HR13.6 (95\% CI 4.63 to 39.7$) ~ P<0.01$ ). HER2 status, when analyzed independent of HR status, was not significantly associated with LRR (HR 1.64, 95\%CI 0.54 to $4.94, P=0.38$ ). However, within the constructed subtypes women with HR+/HER2+ disease, but not those with HR-/HER2+ disease, had significantly increased risk of LRR when compared to HR+/HER2- tumors (HR 6.25 (95\%CI 1.49 to 6.2 ), $P=0.01$ and HR 2.24 (95\%CI 0.26 to 19.2), $P=0.46$, respectively). Administration of trastuzumab to HER2+ patients did not significantly alter LRR risk (HR 3.87 (95\%CI 0.53 o 28.1), $P=0.18$ ).

On multivariate analysis, $\geq 4$ positive nodes and HR-I HER2- subtype were the strongest predictors of LRR failure (HR 23.4 (95\%CI 4.64 to 117.94) and HR 13.87 (95\%CI 4.96 to 38.8 ), respectively, $P<0.05$ ) (Table 4 ). Other variables that retained significant association with LRR risk were one to three positive nodes (HR 4.75 (95\% CI 1.75 to 2.88), $P=0.02$ ), age at diagnosis $<50$ (HR 3.23 (95\%CI 1.25 to 8.33 ), $P=0.02$ ) and HR+/HER2+ subtype (HR 4.26 (95\%CI 1.05 to 7.33 ), $P=0.04$ ).

We next explored whether women with HR-/HER2tumors could be further stratified for LRR risk by clinical variables. The presence of lymphovascular space invasion was also associated with increased risk of LRR within the HR-/HER2- subtype (29.7\% versus $9.23 \%$, HR $=3.44, P=0.04)$ (Table 5). Similarly, patients with node positive disease had increased probability of LRR at five years compared to those who did not $(23.4 \%$ versus $7.8 \%, \mathrm{HR}=4.44, P=0.01)$ (Table 6). When women with $\geq 4$ nodes were removed from this analysis, LRR among those women with one to three positive nodes remained elevated but did not reach statistical significance $(15.6 \%$ versus $7.8 \%, P=0.11)$.

\section{Discussion}

Classification of breast cancer by biologic subtype has proven to be a strong predictor of distant relapse $[2,3]$. Increasingly, data are emerging to support the role of

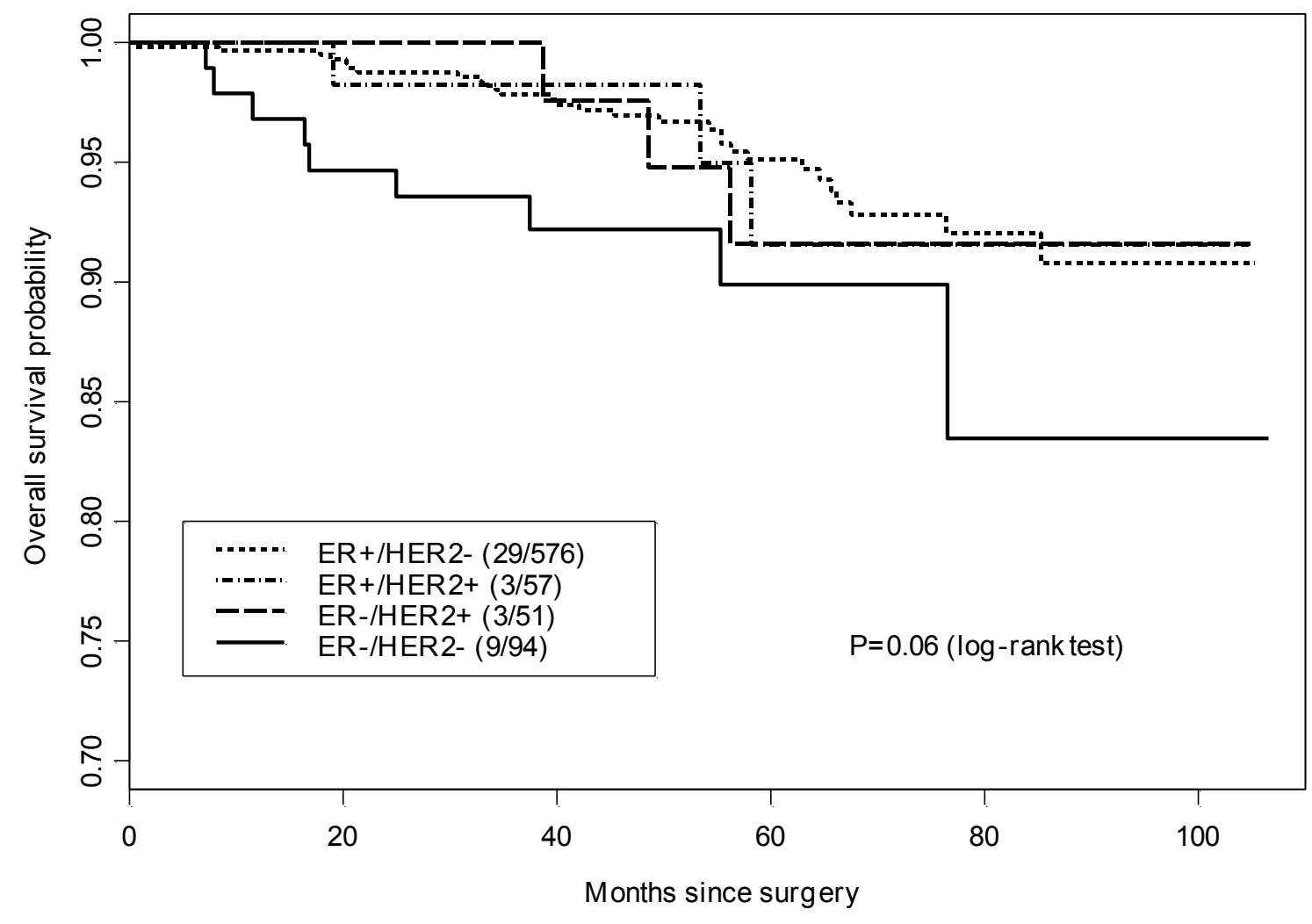

Figure 2 Log rank test of overall survival by tumor subtype. 
Table 3 Univariate Cox PH regression models for local/regional recurrence(LRR)-free survival (Number $=819$ ).

\begin{tabular}{|c|c|c|c|c|}
\hline Variable & $\begin{array}{l}\text { LRR-free } \\
\text { (Number }=800 \text { ) }\end{array}$ & LRR (Number $=19$ ) & HR $(95 \% \mathrm{Cl})$ & $P$-value \\
\hline \multicolumn{5}{|l|}{ Age at diagnosis } \\
\hline$>50$ & 522 & 7 & reference & \\
\hline$<50$ & 278 & 12 & $3.22(1.28$ to 8.33$)$ & 0.01 \\
\hline \multicolumn{5}{|l|}{ T stage } \\
\hline $\mathrm{T} 1$ & 604 & 9 & reference & \\
\hline $\mathrm{T} 2$ & 187 & 8 & $2.95(1.14-7.64)$ & 0.03 \\
\hline T3 & 9 & 2 & $19.8(4.24-92.3)$ & $<0.01$ \\
\hline \multicolumn{5}{|l|}{ Pathologic stage } \\
\hline 1 & 450 & 4 & Reference & \\
\hline$\| A$ and $\| B$ & 335 & 11 & $3.74(1.19-11.7)$ & 0.02 \\
\hline$\|I A\| B B,, \| C$ and IV & 15 & 4 & $31.8(7.94-127)$ & $<0.01$ \\
\hline \multicolumn{5}{|c|}{ Number of positive lymph nodes } \\
\hline 0 & 579 & 7 & reference & \\
\hline $1-3$ & 209 & 10 & $3.94(1.50-10.3)$ & 0.01 \\
\hline$>4$ & 8 & 2 & $23.3(4.83-112)$ & $<0.01$ \\
\hline \multicolumn{5}{|c|}{ Modified Black's nuclear grade } \\
\hline 3 versus 1,2 & & & $6.93(2.30-20.88)$ & $<0.01$ \\
\hline \multicolumn{5}{|l|}{ ER or PR } \\
\hline Negative & 137 & 11 & reference & \\
\hline Positive & 648 & 8 & $0.15(0.06-0.38)$ & $<0.01$ \\
\hline \multicolumn{5}{|l|}{ HER2+ } \\
\hline Negative & 653 & 15 & reference & \\
\hline Positive & 105 & 4 & $1.64(0.54-4.94)$ & 0.38 \\
\hline \multicolumn{5}{|l|}{ Lymphovascular invasion } \\
\hline Negative & 555 & 9 & reference & \\
\hline Positive & 127 & 10 & $5.08(2.06-12.5)$ & $<0.01$ \\
\hline \multicolumn{5}{|c|}{ Received trastuzumab (in HER2+ patients) } \\
\hline No & 78 & 2 & reference & \\
\hline Yes & 26 & 2 & $3.87(0.53-28.1)$ & 0.18 \\
\hline \multicolumn{5}{|l|}{ Systemic therapy } \\
\hline No & 141 & 3 & reference & \\
\hline Yes & 658 & 16 & $1.11(0.32-3.80)$ & 0.87 \\
\hline \multicolumn{5}{|l|}{ Constructed Subtype } \\
\hline $\mathrm{HR}+/ \mathrm{HER} 2-$ & 569 & 5 & reference & \\
\hline $\mathrm{HR}+/ \mathrm{HER} 2+$ & 54 & 3 & $6.25(1.49-26.2)$ & 0.01 \\
\hline HR-/HER2+ & 50 & 1 & $2.24(0.26-19.2)$ & 0.46 \\
\hline HR-/HER2- & 84 & 10 & $13.6(4.63-39.7)$ & $<0.01$ \\
\hline
\end{tabular}

$\mathrm{Cl}$, confidence interval; ER, estrogen receptor; HER2, human epidermal growth receptor 2; PR, progesterone receptor.

Table 4 Multivariable Cox PH regression models for local/ regional recurrence-free survival (Number $=819$ ).

\begin{tabular}{lll}
\hline Variable & HR $(\mathbf{9 5} \% \mathbf{C l})$ & $P$-value \\
\hline 1-3 positive lymph nodes & $4.75(1.75$ to 12.88$)$ & $<0.01$ \\
$\geq 4$ positive lymph nodes & $23.40(4.64$ to 117.94$)$ & $<0.01$ \\
Age $<50$ at diagnosis & $3.23(1.25$ to 8.33$)$ & 0.02 \\
HR+/HER2+ Subtype & $4.26(1.05$ to 7.33$)$ & 0.04 \\
HR-/HER2- Subtype & $13.87(4.96$ to 38.80$)$ & $<0.01$ \\
\hline
\end{tabular}

$\mathrm{Cl}$, confidence interval; HER2, human epidermal growth receptor 2; HR, hormone receptor. tumor biology as a determinant of local and regional failure. In this report, we show that risk of chest wall and regional nodal failure following mastectomy among a cohort of women who did not receive adjuvant radiation therapy is significantly different based on tumor subtype. Specifically, while the overall risk of loco-regional failure is low in this cohort, it rises modestly in women with $\mathrm{HR}+/ \mathrm{HER} 2+$ and significantly in women with HR-/HER2- tumors. Even among women with HR-/HER2- tumors, it is possible to further stratify between those at modest risk and those at marked risk of LRR by the presence of LVI and nodal involvement. 
Table 5 Locoregional recurrence within HR-/HER2- subtype by presence of lymphovascular invasion (LVI) (Number = 80)

\begin{tabular}{lllll}
\hline Variable & Locoregional recurrence & No recurrence & LRR probability at 60 month & $P$-value \\
\hline LVI positive & 4 & 12 & $29.7 \%$ & \\
LVI negative & 6 & 58 & $9.2 \%$ & 0.04 \\
\hline
\end{tabular}

Although direct comparisons with other series is difficult given differences between cohorts, the pattern of relatively higher risk among HR-/HER2- subtypes and lower risk among $\mathrm{HR}+/ \mathrm{HER} 2$ - subtypes seen in our patient population is consistent with other series reporting on LRR following mastectomy. In a series of 1,000 high risk women, Kyndi et al. reported five-year rates of LRR of $20 \%$ among women with HR-/HER2- tumors who received PMRT compared to $3 \%$ in the subset of patients with HR+/HER2- tumors receiving PMRT [10]. Using a six biomarker panel, Voduc et al. reported tenyear LRR of $19 \%$ in tumors negative for ER, PR and HER2 but expressing either CK5/6 or EGFR and 13\% among those tumors negative for all biomarkers [9]. In contrast, ten-year LRR in women with HR+/HER2- and low ki-67 tumors was $8 \%$. This rate of locoregional failure appears high in this subgroup of women with estrogen responsive tumors, which is likely explained by a sizeable number of women in this study who did not receive adjuvant endocrine therapy despite expression of hormone receptors. Thus, the actual rate of LRR following mastectomy in women with $\mathrm{HR}+/ \mathrm{HER} 2$ - tumors is likely closer to that reported by our series and the series by Kyndi et al.

We also did not find adjuvant trastuzumab to impact LRR significantly. Results from both NSABP B-31 and NCCTG N9831 trials demonstrate an approximately $50 \%$ reduction in combined local and regional events in the arm randomized to receive adjuvant trastuzumab [13]. Therefore, it is very likely that the lack of effect we noted in our series is due to the small number of the HER2+ patients who received trastuzumab.

An important difference between our studies and those previously reported is the unexpectedly low rate of LRR seen in our series among women with HR-/ HER2+ tumors (2\%). This stands in distinction with the higher rate of LRR seen among those with HER2+ tumors who also express hormone receptors (HR + /HER2+) within our own series (6.5\% versus $2 \%)$. While only $25 \%$ of the total HER $2+$ cohort received trastuzumab, there were no differences in the proportion of women who received this treatment based on ER status $(28 \%$ in the $\mathrm{HR}+/ \mathrm{HER} 2+$ group versus $24 \%$ in the HR-/HER2+ group). Thus, the differences we report in LRR rates between the two HER2+ subsets may be due to either small sample size or, potentially, differences in responsiveness to trastuzumab-based therapy. Larger datasets are required to further investigate this possibility.

Lastly, our data demonstrate that while tumor subtypes are associated with LRR outcomes, further stratification by clinical variables classically associated with increased risk remains valuable. Thus, women with HR-/HER2- tumors, who have either positive nodes or LVI, are at markedly increased risk of LRR. This is similar to the study by Abdulkarim et al. who reported that LVI and nodal involvement were independently associated with LRR in women with HR-/HER2- breast cancer [17]. These authors also noted that women with early stage, node negative, HR-/HER2- breast cancer treated with breast conserving therapy (BCT) had lower five-year LRR risk compared to a similar cohort treated with mastectomy without radiation. Rates of distant disease were not significantly different. Nonetheless, the authors suggest that the benefit of adjuvant radiation therapy needs to be investigated in all women with HR-/HER2- breast cancer. However, our data show fiveyear LRR risk for women who are node negative to be well under $10 \%$, the threshold generally used for administration of adjuvant radiation. Thus, the majority of such women, if given radiation, would be expected to derive no benefit. In contrast, for women with HR-/ HER2 - tumors and one to three positive nodes, we found a trend towards increase risk of LRR (5.6\% versus $7.8 \%, P=0.11)$. While the difference in our study did not reach statistical significance, this is likely due to small sample size and adjuvant radiation therapy in this subset of HR-/HER2- breast cancers may be warranted to improve both local-regional control and, based on meta-analysis of randomized clinical trials by the Early Breast Cancer Trialists' Collaborative Group [18], survival as well.

Table 6 Locoregional recurrence within HR-/HER2- subtype by lymph node status (Number $=94$ ).

\begin{tabular}{lllll}
\hline Variable & Locoregional recurrence & No recurrence & LRR probability at 60 month & $P$-value \\
\hline Node positive & 5 & 14 & $23.4 \%$ & 0.01 \\
Node negative & 5 & 70 & $7.8 \%$ & 0.00 \\
\hline
\end{tabular}

HER2, HER2, human epidermal growth receptor 2; HR, hormone receptor; LRR, locoregional recurrence. 


\section{Conclusions}

In summary, we found that constructed subtypes can differentiate risk of LRR following mastectomy among a cohort of women generally considered at low risk for LRR. Overall, the risk of LRR in our study remains quite low across subtype. The addition of clinical risk variables to HR-/HER2- subtype can identify a subset of women at marked increase for LRR and for whom adjuvant radiation may be considered.

\section{Abbreviations}

Cl: confidence interval; CK: cytokeratin; DCIS: ductal carcinoma in situ; EGFR: epidermal growth factor receptor; ER: estrogen receptor; FISH: fluorescence in situ hybridization; HR: hormone receptor; HER2: human epidermal growth receptor 2; IHC: immunohistochemistry; LRR: locoregional recurrence; LVI: lymphovascular space invasion; NSABP: National Surgical Adjuvant Breast and Bowel project; NCCTG: North Central Cooperative Trials Group; PMRT: post-mastectomy radiation therapy; PH: proportional hazards; PR: progesterone receptor.

\section{Author details}

${ }^{1}$ Department of Surgical Oncology, University of Texas MD Anderson Cancer Center, 1515 Holcombe Blvd, Houston, TX 77030, USA. ${ }^{2}$ Department of Breast Medical Oncology, University of Texas MD Anderson Cancer Center, 1515 Holcombe Blvd, Houston, TX 77030, USA. ${ }^{3}$ Department of Biostatistics, University of Texas MD Anderson Cancer Center, 1515 Holcombe Blvd, Houston, TX 77030, USA. ${ }^{4}$ Department of Radiation Oncology, University of Texas MD Anderson Cancer Center, 1515 Holcombe Blvd, Houston, TX 77030, USA.

\section{Authors' contributions}

LD participated in data collection and preparation of the manuscript. XM and $J L$ led the data analysis and participated in manuscript preparation. $A B$ participated in data analysis. EAM, HMK, KKH, GVB, TAB and FMB all participated in data interpretation and critical revision of the manuscript. IB conceived of the study, participated in data collection and analysis and drafting of the manuscript. All authors have read and approved the final manuscript for publication.

\section{Competing interests}

The authors declare that they have no competing interests.

Received: 8 February 2012 Revised: 17 April 2012

Accepted: 23 May 2012 Published: 23 May 2012

\section{References}

1. Perou CM, Sorlie T, Eisen MB, van de Rijn M, Jeffrey SS, Rees CA, Pollack JR, Ross DT, Johnsen H, Akslen LA, Fluge O, Pergamenschikov A, Williams C, Zhu SX, Lonning PE, Borresen-Dale AL, Brown PO, Botstein D: Molecular portraits of human breast tumours. Nature 2000, 406:747-752.

2. Sorlie T, Perou CM, Tibshirani R, Aas T, Geisler S, Johnsen H, Hastie T, Eisen MB, van de Rijn M, Jeffrey SS, Thorsen T, Quist H, Matese JC, Brown PO, Botstein D, Eystein Lonning P, Borresen-Dale AL: Gene expression patterns of breast carcinomas distinguish tumor subclasses with clinical implications. Proc Natl Acad Sci USA 2001, 98:10869-10874.

3. Sotiriou C, Neo SY, MCShane LM, Korn EL, Long PM, Jazaeri A, Martiat P, Fox SB, Harris AL, Liu ET: Breast cancer classification and prognosis based on gene expression profiles from a population-based study. Proc Natl Acad Sci USA 2003, 100:10393-10398.

4. Rouzier R, Perou CM, Symmans WF, Ibrahim N, Cristofanilli M, Anderson K, Hess KR, Stec J, Ayers M, Wagner P, Morandi P, Fan C, Rabiul I, Ross JS, Hortobagyi GN, Pusztai L: Breast cancer molecular subtypes respond differently to preoperative chemotherapy. Clin Cancer Res 2005, 11:5678-5685.

5. Carey LA, Perou CM, Livasy CA, Dressler LG, Cowan D, Conway K, Karaca G, Troester MA, Tse CK, Edmiston S, Deming SL, Geradts J, Cheang MC, Nielsen TO, Moorman PG, Earp HS, Millikan RC: Race, breast cancer subtypes, and survival in the Carolina Breast Cancer Study. JAMA 2006, 295:2492-2502.

6. Cheang MC, Voduc D, Bajdik C, Leung S, McKinney S, Chia SK, Perou CM, Nielsen TO: Basal-like breast cancer defined by five biomarkers has superior prognostic value than triple-negative phenotype. Clin Cancer Res 2008, 14:1368-1376.

7. Millar EK, Graham PH, OToole SA, McNeil CM, Browne L, Morey AL, Eggleton S, Beretov J, Theocharous C, Capp A, Nasser E, Kearsley JH, Delaney G, Papadatos G, Fox C, Sutherland RL: Prediction of local recurrence, distant metastases, and death after breast-conserving therapy in early-stage invasive breast cancer using a five-biomarker panel. J Clin Oncol 2009, 27:4701-4708.

8. Nguyen PL, Taghian AG, Katz MS, Niemierko A, Abi Raad RF, Boon WL, Bellon JR, Wong JS, Smith BL, Harris JR: Breast cancer subtype approximated by estrogen receptor, progesterone receptor, and HER-2 is associated with local and distant recurrence after breast-conserving therapy. J Clin Oncol 2008, 26:2373-2378.

9. Voduc KD, Cheang MC, Tyldesley S, Gelmon K, Nielsen TO, Kennecke H: Breast cancer subtypes and the risk of local and regional relapse. J Clin Oncol 2010, 28:1684-1691.

10. Kyndi M, Sorensen FB, Knudsen H, Overgaard M, Nielsen HM, Overgaard J: Estrogen receptor, progesterone receptor, HER-2, and response to postmastectomy radiotherapy in high-risk breast cancer: the Danish Breast Cancer Cooperative Group. J Clin Oncol 2008, 26:1419-1426.

11. Fernando SA, Edge SB: Evidence and controversies in the use of postmastectomy radiation. J Natl Compr Canc Netw 2007, 5:331-338.

12. Horii R, Akiyama $F$, Ito $Y$, Iwase $T$ : Assessment of hormone receptor status in breast cancer. Pathol Int 2007, 57:784-790.

13. Romond EH, Perez EA, Bryant J, Suman VJ, Geyer CE Jr, Davidson NE, TanChiu E, Martino S, Paik S, Kaufman PA, Swain SM, Pisansky TM, Fehrenbacher L, Kutteh LA, Vogel VG, Visscher DW, Yothers G, Jenkins RB, Brown AM, Dakhil SR, Mamounas EP, Lingle WL, Klein PM, Ingle JN, Wolmark N: Trastuzumab plus adjuvant chemotherapy for operable HER2-positive breast cancer. N Engl J Med 2005, 353:1673-1684.

14. Kaplan $E$, Meier P: Nonparametric estimation from incomplete observations. J Am Stat Assoc 1958, 53:457-481.

15. Mantel N: Evaluation of survival data and two new rank order statistics arising in its consideration. Cancer Chemother Rep 1966, 50:163-170.

16. Cox D: Regression models and life-tables (with discussion). J R Stat Soc 1972, Series B 34:187-220.

17. Abdulkarim BS, Cuartero J, Hanson J, Deschenes J, Lesniak D, Sabri S: Increased risk of locoregional recurrence for women with T1-2NO triplenegative breast cancer treated with modified radical mastectomy without adjuvant radiation therapy compared with breast-conserving therapy. J Clin Oncol 2011, 29:2852-2858.

18. Clarke M, Collins R, Darby S, Davies C, Elphinstone P, Evans E, Godwin J, Gray R, Hicks C, James S, Mackinnon E, McGale P, McHugh T, Peto R, Taylor C, Wang Y: Effects of radiotherapy and of differences in the extent of surgery for early breast cancer on local recurrence and 15-year survival: an overview of the randomised trials. Lancet 2005, 366:2087-2106.

doi:10.1186/bcr3197

Cite this article as: Dominici et al:: Implications of constructed biologic subtype and its relationship to locoregional recurrence following mastectomy. Breast Cancer Research 2012 14:R82. 